\title{
Soon the Recovery will Likely be the Rule and Death will be an Exception in COVID-19
}

\author{
Rano Mal Piryani ${ }^{1}$, Suneel Piryani ${ }^{2}$, Ganesh Dangal ${ }^{3}$, Muzaherul Huq ${ }^{4}$
}

Author Info:

${ }^{1}$ Professor of Internal Medicine, Head Department of Internal Medicine and Chief CoordinatorHealth Professions Training Committee, Coordinator COVID-19 Task Committee, Universal College of Medical Sciences, Bhairahawa, Nepal

${ }^{2}$ Public Health Consultant, Karachi Pakistan

${ }^{3}$ Professor and Academic Chief of Department of Obstetrics and Gynecology, Kathmandu Model Hospital, Nepal

${ }^{4}$ Former Regional Advisor, WHO, SEARO, Bangaladesh

\section{Corresponding Author:}

Dr. Rano Mal Piryani,

E mail/Contact:

rano.piryani@gmail.com

r_piryani@hotmail.com

\begin{abstract}
Since the cluster of cases of SARS-CoV-2 first reported in December 2019, the number of COVID-19 cases and deaths have rapidly been rising but cumulative percentage of deaths has been decreasing from April 2020 globally and also in South Asian countries. Knowing the number of reported deaths during a period of the pandemic is not enough but knowing the number of excess deaths in a given population over the time may carry weight which is yet to be known globally. The COVID-19 pandemic may lead to increased deaths from some other communicable diseases such as Tuberculosis, dengue, and fewer deaths from some causes such as road accidents. Hence, both reported mortality figures and excess mortality figures are required to understand the death toll of the pandemic COVID-19.
\end{abstract}

Around one third patients are asymptomatic transmitting infection and among symptomatic, $80 \%$ has mild to moderate disease managed at outpatients settings in home isolation; $15 \%$ develop lower respiratory tract infection require hospitalization and recover; $3-5 \%$ need intensive care and may need ventilator support while $0.5-1 \%$ of patients may die.

We are of the opinion that in case of COVID-19, soon the recovery will likely be the rule and death will be an exception and our opinion is based on the facts of better understanding of COVID-19 infection and disease and its prevention, control and supportive treatment strategy even in the absence efficacious vaccine for prevention and effective medicine for cure and prophylaxis. The condition is that we have to continue to follow non-pharmacological interventions for containment and mitigation with true public health spirit. Keywords: COVID-19, Deaths, Pandemic, NonPharmacological interventions

\begin{tabular}{|c|c|c|}
\hline QR Code & \multicolumn{2}{|l|}{ Article Info } \\
\hline \multirow{5}{*}{ 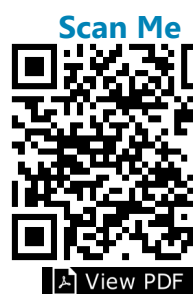 } & Received: 17 October 2020; & Published Online: 24 January 2021 \\
\hline & \multicolumn{2}{|l|}{ How to cite this article in Vancouver Style? } \\
\hline & \multicolumn{2}{|c|}{$\begin{array}{l}\text { Piryani RM, Piryani S, Dangal G, Muzaherul Huq. Soon the recovery will likely be the rule and death will be an } \\
\text { exception in COVID-19. Europasian J Med Sci. 2020; 3(1). https://doi.org/10.46405/ejms.v3i1.206 }\end{array}$} \\
\hline & \multicolumn{2}{|l|}{ Disclaimer } \\
\hline & Conflict of Interest: None Declared; & Source of Support: Nil \\
\hline \multicolumn{3}{|c|}{$\begin{array}{l}\text { Copyright }(2021 \text { by author(s). This is an open access article distributed under the terms of the Creative Commons Attribution } \\
\text { International License } 4.0 @(\Phi) \text { (http://creativecommons.org/licenses/by/4.0/) which permits unrestricted use, distribution, and } \\
\text { reproduction in any medium, provided the original work is properly cited. The Europasian Journal of Medical Sciences (EJMS) (www. } \\
\text { europasianjournals.org) is an official Journal of Nirvana Psychosocial Care Center \& Ressearch Institute (www.nirvanapscc.com). The } \\
\text { Journal as well as publisher remain neutral with regards to any jurisdictional claims in any published articles, its contents and the } \\
\text { institutional affiliations of the authors. }\end{array}$} \\
\hline
\end{tabular}




\section{Soon the recovery will likely be the rule and death will be exception in COVID-19}

As of October 17, 2020, the COVID-19 is affecting 215 countries and territories around the world and 2 international conveyances; around 40 million new cases were reported, more than 1.1 million deaths occurred and around 30 million patients recovered worldwide. The cumulative calculated death percentage was $2.81 \%$ by October 15; and the trend has been decreasing since April (Table 1). ${ }^{1}$

As on 11.00 am IST October 16, 2020., eight South Asian Association of Regional Cooperation (SAARC) countries (Afghanistan, Bangladesh, Bhutan, India, Maldives, Nepal, Pakistan and Sri Lanka) reported more than 8 million $(8,255,348)$ new cases, more than one million $(126,795)$ deaths and more than 7 million $(7.190,415)$ patients recovered. (Table 2) The cumulative calculated death percentage and recovery percentage were around $1.53 \%$ and $87.1 \%$ respectively (Table 2 ). ${ }^{2}$ The cumulative death percentage in South Asia is around half of the global.

As per COVID-19 Status of SAARC Countries till midnight (GMT+1.48) April 6, 2020, the total 8091 new cases were reported and 185 patients were declared dead due to COVID-19; the cumulative death percentage was $2.28 \% .^{3}$ Since then it is decreasing.

In fact, we need to know/identify not merely the reported cases but actual number of cases at the given point of time. We don't have actual and accurate statistics of asymptomatic cases as quite number of cases are asymptomatic, sufficient number of mild cases may not be reporting to healthcare facility and, the number of tests performed by countries varied, the sensitivity of the RT-PCR is around $70 \%$ (the false negative cases around $30 \%)^{4}$ and the testing has not been performed on the entire population. So, the actual number of cases is estimated to be higher than the reported cases. Hence, the actual number of deaths may likely be less than actual reported deaths. ${ }^{4}$

Knowing the number of reported deaths during a period of the pandemic is not enough but knowing the number of excess deaths in a given population over the time may carry weight which is yet to be known/reported. Recently study from USA reported excess deaths in 5 months from March to July 2020; these additional deaths could be indirectly related because people avoided emergency care during the early part of pandemic. ${ }^{5}$ There is no excess death data reported by any other countries till date.

Also, the COVID-19 pandemic may lead to increased deaths from some other diseases such as tuberculosis, dengue, and fewer deaths from some other causes such as road accidents. ${ }^{6}$ Hence, both reported mortality figures and excess mortality figures are required to understand the death toll of the pandemic COVID-19. ${ }^{6}$

At this point in time no efficacious vaccine for prevention and effective medicine for cure and prophylaxis are available and drugs which are being used decrease the length of stay in hospital and mortality too. ${ }^{7}$

As per the Center for Disease Control and Prevention (CDC) USA, up to one third of the patients infected with COVID-19 may never develop any symptoms (asymptomatic) but they can transmit the disease. ${ }^{8}$

Table 1. Reported new cases, deaths and cumulative death percentage globally.

\begin{tabular}{cccc}
\hline Month of the year & Cumulative New Cases & Cumulative Death & Cumulative Death \% \\
\hline January, 2020 & 11,950 & 259 & $2.16 \%$ \\
Jan-Feb, 2020 & 86,606 & 2,977 & $3.43 \%$ \\
Jan-Mar, 2020 & 862,646 & 44,226 & $5.12 \%$ \\
Jan-Apr, 2020 & $3,256,718$ & 235,292 & $7.22 \%$ \\
Jan-May, 2020 & $6,241,232$ & 377,825 & $6.05 \%$ \\
Jan-June, 2020 & $10,568,118$ & 513,284 & $4.86 \%$ \\
Jan- July 2020 & $17,740,185$ & 689,990 & $3.88 \%$ \\
Jan- Aug 2020 & $25,653,706$ & 859,550 & $3.35 \%$ \\
Jan- Sep 2020 & $34,260,551$ & $1,024,095$ & $2.99 \%$ \\
Jan-Oct, 2020 & $39,153,043$ & $1,102,432$ & $2.81 \%$ \\
\hline
\end{tabular}


Table 2: Highlights \& Situation Overview as on dated $16^{\text {th }}$ August 2020 at 11:00AM first COVID-19 Cases in the SAARC Member States.

\begin{tabular}{lcc|c|}
\hline Country & Total Cases & Total Deaths & Recovered \\
\hline Afghanistan & 40,026 & 1481 & 33,447 \\
Bangladesh & $3,84,559$ & 5608 & $2,99,229$ \\
Bhutan & 316 & 0 & 296 \\
India & $73,70,468$ & $1,12,161$ & $64,537,79$ \\
Maldives & 11,113 & 35 & 9931 \\
Nepal & 121,745 & 694 & 84,518 \\
Pakistan & $3,21,877$ & 6621 & $3,05,835$ \\
Sri Lanka & 5244 & 13 & 3380 \\
Total & $\mathbf{8 2 , 5 5 , 3 4 8}$ & $\mathbf{1 , 2 6 , 6 1 3}$ & $\mathbf{7 1 , 9 0 , 4 1 5}$
\end{tabular}

Among symptomatic patients, $80 \%$ have only very mild to moderate disease and can be managed as outpatients and kept in home isolation; 15\% develop lower respiratory tract infection and may require hospitalization and recover; $3-5 \%$ requires intensive care and may need ventilator support and $0.5-1 \%$ of patients may die. ${ }^{8}$ The data may little bit vary between continent to continent, country to country, within country between state to state and within state between district to district. A physician, epidemiologist and fellow in infectious diseases from USA believes that infection fatality rate values could be as different as $0.05 \%$ to $1 \%$ ${ }^{9}$ and it seems to be possible from the decreasing trend seen in cumulative death rate worldwide and also in SAARC countries. ${ }^{1}$

We are of the opinion that in case of COVID-19, soon the recovery will likely be the rule and death will be an exception. Our opinion is based on the facts that mortality has been decreasing because of better understanding of transmission of infection, spread of infection and pathophysiology of disease; availability of comparably better diagnostic tools; better understanding of natural history of infection and disease; comparably better management of severe and critically ill patients; better understanding of healthcare professionals about the infection and its prevention and diseases and its management, use of personal protective equipment (PPE) and importance of isolation and quarantine; better understanding of public health professionals about contact tracing mechanism, risk communication and risk reduction strategy; better understanding of public about the infection and disease, its prevention and management; comparably better coordination among the World Health Organization and other International, National and Local organizations, collaborators, academician and scientists. ${ }^{10,}$; provided we have to continue to follow the basics i.e. follow and implement infection prevention and control measures (handwashing/hand-hygiene, droplet precautions, contact precautions, aerosol precautions, respiratory etiquette, environmental hygiene, masking) and physical distancing until effective and efficacious vaccine/s with no major adverse effects for mass vaccination are get available (herd immunity develops) and/or effective and efficacious drugs without major side effects for prophylaxis are get available, accessible and affordable and specific drug/s for treatment are get available, accessible and affordable. And we have to sustain our efforts in containing and mitigating the pandemic with the strategy of contact tracing, testing, isolation of cases and quarantine the contacts with active community participation.

Furthermore, we agree with conviction that the death is $100 \%$ loss of person and family but truth is that the death is a reality and mortality is associated with every disease, be it communicable disease or non-communicable disease unless infection/ disease has reached at the stage of eradication. In case of exponentially growing, highly contagious communicable infection/disease like COVID-19, the urgent need and immediate target is to contain the infection and reduce the mortality and the 
people knows it, aware about it and have a capacity to contain the infection and reduce the mortality and take left over fear out of the mind of public but scientific community continue to study the behavior of the virus in order to understand more about its short-term and long-term impact.

\section{REFERENCES}

1. COVID-19- Coronavirus Pandemic. https://www. worldometers.info/coronavirus/ Accessed on October 17, 2020

2. Highlights and Situation Overview COVID-19 cases in the SAARC Member States http://www.covid19sdmc.org Accessed on October 17, 2020

3. Piryani RM, Piryani S, Shah JN. Nepal's Response to Contain COVID-19 Infection. JNHRC 2020; 18 (1): 128-134. doi: 10.33314/jnhrc.v18i1.2608.

4. Coronavirus (COVID-19) Mortality Rate. Available at https://www.worldometers.info/coronavirus/ coronavirus-death-rate/ Accessed on October 17, 2020.

5. Profound Human Toll' in Excess Deaths From COVID-19 Calculated in Two Studies - Medscape - Oct 12, 2020. https://www.medscape.com/ viewarticle/938996

6. Excess mortality from the Coronavirus pandemic (COVID-19) https://ourworldindata.org/excessmortality-covid. Accessed on July 12, 2020

7. Are New COVID-19 Treatments More Important Than a Vaccine? - Medscape - Oct 06, 2020. https:// www.medscape.com/viewarticle/938578.

8. Center for Disease Control and Prevention. Coronavirus Disease 2019- Clinical Care Guidance updated June 30, 2020. Available at: https://www. cdc.gov/coronavirus/2019-ncov/hcp/clinicalguidance-management-patients.html Accessed on July 11,2020

9. Saurabh Jha. John Ioannidis Explains His COVID Views - Medscape - Jul 15, 2020 https://www. medscape.com/viewarticle/933977. Accessed on July 30, 2020

10. COVID-19 Treatment Guidelines Panel. Coronavirus Disease 2019 (COVID-19) Treatment Guidelines. National Institutes of Health. Available at https:// www.covid19treatmentguidelines.nih.gov/. Accessed on July 11, 2020.

11. WHO I Country \& Technical Guidance - Coronavirus disease (COVID-19). [Internet] WHO. World Health Organization. Available at:

12. https://www.who.int/emergencies/diseases/novelcoronavirus-2019/technical-guidance Accessed on July 11, 2020. 